\title{
Power Scenario Prospects for Micro Grid
}

\author{
P. Nivedhitha ${ }^{1}$ \\ ${ }^{I}$ Department of Electrical and Electronics Engineering, Thiagarajar College of Engineering, Madurai, India
}

Abstract: This paper gives an overview of the developing Micro Grid technology for power systems. To overcome energy crisis, renewable energy sources prove to be an alternate. It briefs on the technical outlook, applications, and advantages of Micro grid over the ordinary passive macro grids, thus widening its scope for research and development globally.

Keyword: Renewable energy resources, Centralised grid, Micro grid, Distributed Generation

\section{INTRODUCTION}

Energy is the lifeblood of modern civilisation. With the emerging thirst for domestic and industrial power, energy management has become a challenge. The time has ripened to adopt evolutionary strategies across the globe to provide consistent, cost effective, affordable, green and quality power for socio-economic, environmental and technical benefits. One such strategy is Micro Grid that integrates distributed on-site generation stations of end-users, with or without the Centralised grid, making electricity bidirectional. It perfects power for a secure and sustainable future in energy sector.

\section{BASIC CONCEPTS OF MICRO GRID}

Micro grid is an aggregated concept with participation of available supply and demand side energy resources in low-voltage distribution grids, via application of emerging technologies in power electronics interfaces, modern controls and nanotechnology. A sample Micro grid is shown in Fig. 1. Such self-sufficient 'future guaranteed' systems can be operated in a non-autonomous way, if interconnected to the grid. Otherwise it can be operated in an autonomous way, if disconnected from the main grid.

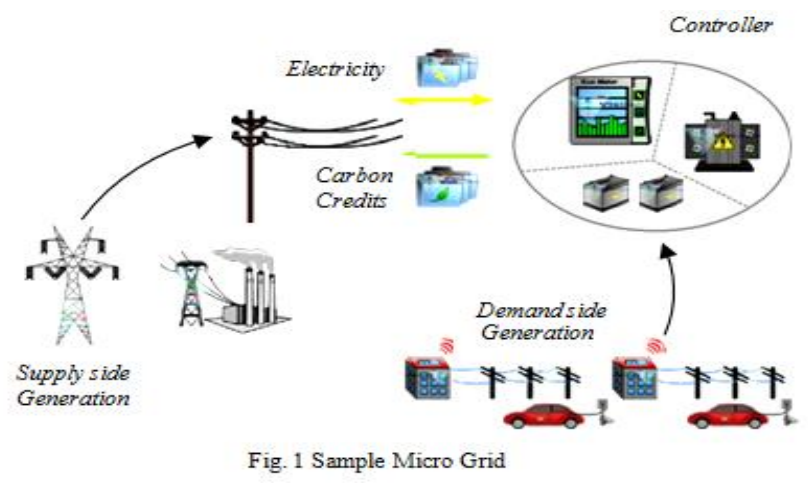

III. NECESSITY FOR MICRO GRID

The global consumption of electricity is increasing alarmingly, as shown in Fig. 2. Currently two billion people around the world have no access to electricity at all. It is of high priority to address and change the existing energy scenario, making a march towards 'Energy to All' globally. Renewable Energy resources can find an acute solution to this issue. It is estimated that the renewable energy resources across the globe has the potential to supply 3087 times the current electricity demands. 


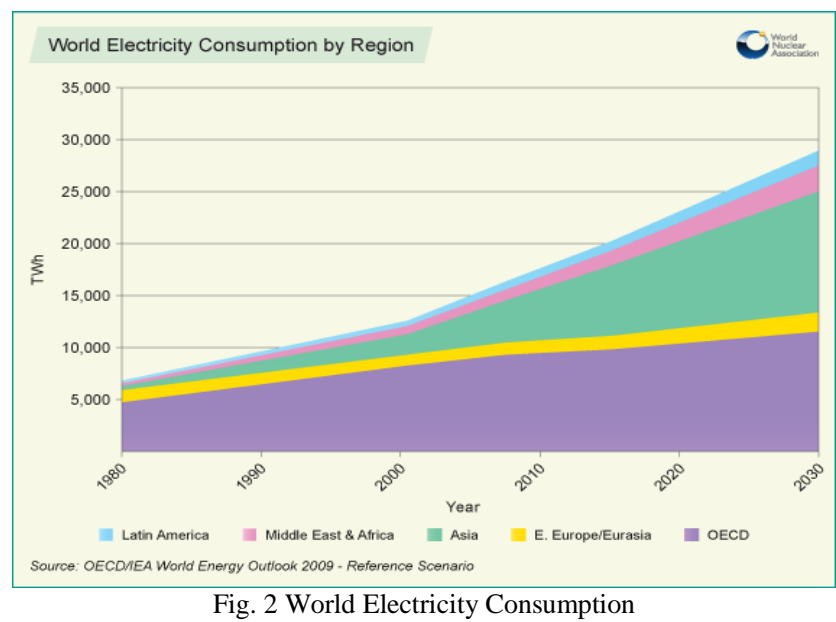

To make use of the fullest available potential of renewable energy resources, self-sufficient on-site generation plants like solar power, wind, fuel cells, and biomass can be installed, ensuring the exact needs of the Micro grid constituents duly served while networking with the Centralised grid.

The Government is bound to encourage such demand side generation by providing subsidies to consumers, in the interest of 'energising' the country. The consumer can also seek revenue for the surplus energy generated by the domestic plant, by supplying it to the Centralised grid. This 'Energy by All' phenomenon in turn provides an opportunity for individuals to significantly participate in the active energy growth of a nation. Thus, Micro grids open the door for a new, innovative electrical ecosystem.

\section{BENEFITS OF MICRO GRID}

Micro grid, though not a replacement for the national grid as a whole, improves certain aspects remarkably. It paves way for every remote area to have access to uninterrupted power supply. It offers a wide range of socio-economic, technical and environmental benefits to the consumer that includes:

\section{1) Economic Benefits:}

- Local Consumer Benefit - Micro grids can accelerate economies opening new avenues for job opportunity at the local level. Cost per unit of energy is reduced. This encourages a new electricity generation business model that is more efficient with the available renewable resources, and likely to spur continuous innovation.

- Generates Revenue - Transmission Cost as far as the end user is concerned is reduced significantly. Supports new entrepreneurial energy markets, allowing customers to sell excess production of energy into the bulk energy market. These smart Micro grids also set the stage for additional consumer revenues from plug-in electric vehicles and carbon credits. Analogous to 'Drops of water make an Ocean', Micro grids in unison will lead to 'Energy Revolution'.

\section{2) Technical benefits:}

- Reliability - Local power generation and storage allow certain portions of the grid to operate independent of the National grid when necessary, thus avoiding black outs. Redundant sources enable continuous power flow even during environmental interruptions in the system.

- Better Performance Characteristics - There is nearly $82 \%$ annual transmission loss reduction in Micro grids than the normal passive grids, thus serving the purpose of energy management. The voltage regulation is reduced by $57 \%$ when compared with passive networks. Also 50\% reduction in the peak load supply by the Centralised National Grid is observed by the use of Micro Grids.

- Stability - Independent local control of generators, batteries and loads are based on frequency droops and the voltage levels at the terminal of each device and hence it is highly stable.

- Compatibility - Micro grids are completely compatible with existing utility grid. They may be considered as functional units that support the growth of the existing system in an economically and environment friendly way.

- Scalability - Micro grids can grow through additional installation of generators, storage elements and loads. Such an extension usually requires an incremental new planning of the Micro grid and can be performed in a parallel, modular manner in order to scale up to higher power production and consumption levels. 


\section{3) Environmental Benefits:}

- Reduces Carbon Print - The smart Micro grid can reuse the waste energy produced during generation of electricity to heat up buildings, sterilization and cooling. This bottom-up consumer approach reduces the reliance on fossil fuel and green house gases emission, thus enabling carbon credits.

\section{TECHNICAL ASPECTS OF MICRO GRID}

Prima-facie to establishing a Micro grid, the following aspects are to be analysed:

- Energy Audit on available on-site renewable energy resources, controllable loads, energy storage, combined heat and power facilities, cooling.

- Switchgear utility interconnection including low-cost switches, interconnection study, and protection schemes study.

- Standards and protocols, control algorithms and software for integration with energy management system utilities, real-time signals processing, local SCADA access, power electronics devices.

- Modelling \& Analysis, system integration, testing, and validation of the local site.

A Micro grid can operate in two modes namely:

- Grid Connected Mode - Micro grid is connected to the Centralised Electricity Power Grid.

- Isolated Mode - Micro grid operates autonomously, disconnected from the Centralised grid.

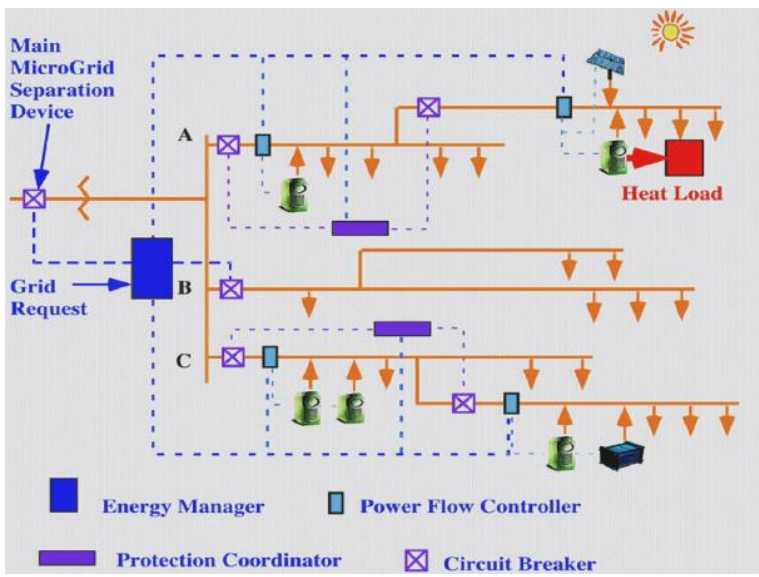

Fig. 3 Micro Grid Architecture

Infrastructure of Micro grid technology, as in Fig. 3 includes the following:

1) Micro source Controller comprising of power electronic interfaces such as inverters, DC interfaces, offer control possibilities that go beyond simple control of real power.

The requirements to control a Micro grid provided by each Micro source are:

- Control of real and reactive power - In both DC and AC Micro sources, the DC voltage generated is converted to AC using a voltage inverter to maintain the power factor at the interfacing end, connected via an inductor with the Centralised grid.

- Voltage regulation through droop - Voltage regulation is necessary for reliability and stability. In a Micro Grid, which is typically radial, the problem of large circulating reactive currents is immense. With small errors in voltage set points, the circulating current can exceed the ratings of the Micro sources. Therefore, with Q-point should be maintained constant between the highly inductive and capacitive loads.

- Fast load tracking and storage - In isolated mode of operation, when a new load comes on line, the initial energy balance is satisfied by the system's inertia, which results in a slight reduction in system frequency. To balance that super capacitors or batteries are added with the Micro source.

2) Energy Manager is a "supervisory controller" that meets operational objectives and constraints by dispatching devices. The objective will typically be to minimize the total energy bill within the constraints of the system, which might include serving heat and electrical loads, fuel costs, and equipment performance specifications, limitations due to safety, fuel supply limitations, and restrictions on noise or pollutant emissions.

3) Protection Coordinator, which rapidly isolates feeder faults within the Micro Grid and communicates feeder status changes to the Energy Manager. 
4) Control Algorithms facilitates robust behaviour of energy manager and protection co-ordinator, the information infrastructure, as shown in Table I needs to be fault-tolerant and be able to deal with a dynamic environment.

TABLE I

MICRO GRID INFORMATION CONTROL

\begin{tabular}{|c|c|c|}
\hline & Non real-time & Real Time \\
\hline శ్రુ & $\begin{array}{c}\text { Data Aggregation, } \\
\text { Logging }\end{array}$ & $\begin{array}{l}\text { Voltage droop control, } \\
\text { Frequency droop control }\end{array}$ \\
\hline 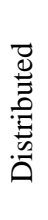 & $\begin{array}{l}\text { Smart Metering, System } \\
\text { monitoring, Demand side } \\
\text { management, Peak } \\
\text { shaving, Power quality } \\
\text { analysis, Market \& } \\
\text { Trading }\end{array}$ & $\begin{array}{c}\text { Load shedding (Generated } \\
\text { power }<\text { Demand), Power } \\
\text { quality mitigation, } \\
\text { Resynchronisation after } \\
\text { islanding (isolated mode). }\end{array}$ \\
\hline
\end{tabular}

5) Communication Protocols, like the standard IEC 61850 series protocols which provide object models for the information exchange is used.

6) Micro grid Integration Standard usually used is the IEEE 1547 series for design, operation and integration of Micro grids with the Centralised grid.

\section{APPLICATIONS OF MICRO GRID}

Micro grid opens up an all new Corporate Energy Market. Germany leads the globe in production of electricity from renewable resources, followed by United Kingdom, Indonesia and Italy. In India, it has become increasingly popular in the very recent years, as shown in Fig. 4 and Micro grid is sure to make a remarkable mark in this sector.

\section{A. Military Bases}

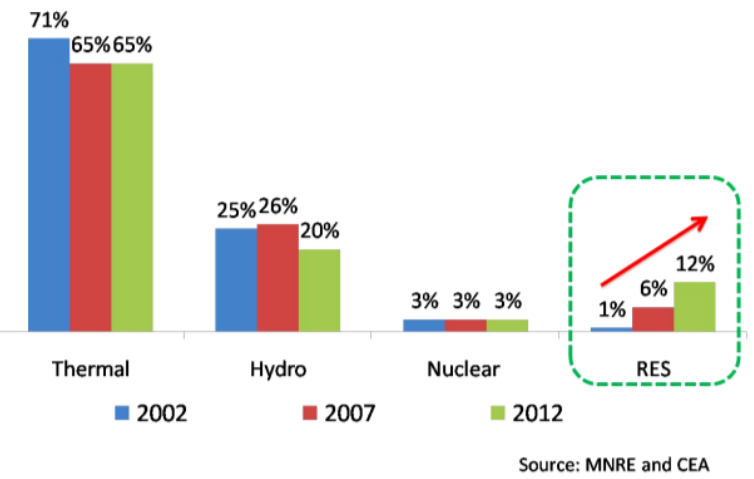

Fig. 4 Increasing share of renewable energy in India

Military bases are usually located in remote locations of a country; fuel is trucked to run its generators. Micro grid can prove to be an alternative for this fragile source of power. The Military Base could be made energy-sufficient by building a Micro grid with the renewable resources available on-site. US Army Fort Bragg, North Carolina has made the initiative and is running successfully.

\section{B. Industrial \& Educational Campuses}

A Micro grid can be built in such campuses that ensure redundant electricity supply with the resources available. It eliminates outages, minimize power disturbances, moderate an ever-growing demand and curb greenhouse gas emissions. IIT, USA, Intel and Ford have established Micro grid in its campus. 


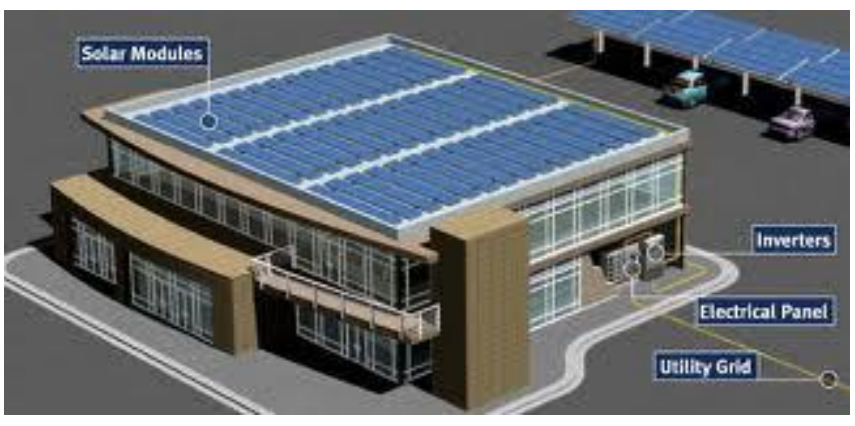

\section{Remote Villages}

Fig. 5 Commercial Micro grid on-site

This segment represents the greatest number of Micro grids currently operating globally, but it has the smallest average capacity. While many systems have historically featured diesel distributed energy generation, the largest growth sector is solar photo voltaics. Wind mills with Micro turbines are projected to play a growing role as well. Gram Power established by Mr. Yashraj Khaitan and Mera Gao Power in India commercialised Micro grid technology and turned out to be one the best clean technology innovations.

\section{Community Micro grids}

Community energy Micro grids are for people, not utility companies. CMGs are about tapping into, distributing, and using $100 \%$ locally produced renewable energy with local labour and materials. Community Micro grids can provide ample local and renewable power without connecting to the main grid. This lowers the energy costs and peak demand. Santa Rita Jail in California's Alameda County has built smart Micro grid and has saved $50 \%$ of its energy expenses.

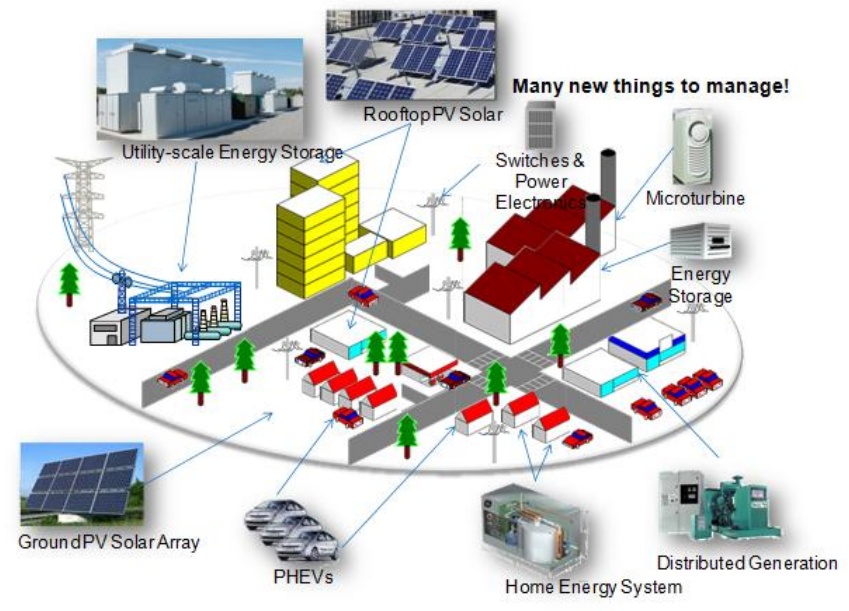

Fig. 6 Community Micro grid

\section{FUTURE SCOPE OF MICRO GRID}

Micro Grid promises wide scope of research in:

- Better performance of frequency and voltage control methods under various operation modes.

- Improvement of Distributed Resource technology and development of suitable architectures and control technologies for Micro grid.

- Development of improved approaches for interfacing Micro grids to the centralised grid.

- Transformation of Micro grid system into an intelligent, robust energy delivery system in the future by providing significant reliability and security.

- To improve transition between the grid connected and isolated operating modes.

- Deployment of Micro grid business parks.

\section{Challenges OF Micro Grid}

- The initial cost of installation of on-site production plants is more.

- Availability of funds at higher rates of interest.

- Synchronisation of Micro grid with Centralised grid is difficult.

- Quality of power generated at each Micro source should be improved. 
- Space constraint; technology at its naive stage.

- Lack of awareness among the public.

\section{CONCLUSION}

It is the responsibility of the Government to provide capital subsidies, and loans at cheaper rates to the consumers for establishment of a Micro grid. It also has to provide such consumers with energy credits for sharing the energy burden of the Government. Awareness campaigns should be convened.

The intelligent transformation in infrastructure and policies of Micro grid is the key to achieve sustainable, environmental, and economic energy for today's citizens and future generations. Thus, Micro Grid promises energy surety for the future.

\section{ACKNOWLEDGMENT}

The author is thankful to the authorities of "Thiagarajar College of Engineering, Madurai - 625015", for providing all the facilities to do this research work.

\section{References}

[1] Christine Schwaegerl, Advanced Architecture and Control Concepts for more Micro grids, Siemens AG, Germany, December, 2009.

[2] Robert Liam Dohn, The Business Case for Micro grids, Siemens, Germany, 2009.

[3] Robert Lasseter, Abbas Akhil, Chris Marnay, John Stephens, Jeff Dagle, Ross Guttromson, A. Sakis Meliopoulous, Robert Yinger, and Joe Eto, White Paper on Integration of Distributed Energy Resources -The Micro grid Concepts, Consortium for Electric Reliability Technology Solutions, December, 2001.

[4] Bren Koposki, Charlie Vartanian, Micro grid Standards and Protocols, DOE Micro grid Planning Meeting.

[5] The Value of Smart Distribution and Micro grids, Galvin Electricity Initiative, January 2010.

\section{BIOGRAPHIES}

P. Nivedhitha is doing her B.E. Degree in Electrical and Electronics Engineering at Thiagarajar College of Engineering, Madurai. Her field of interest is Power Systems and Energy. 